\title{
Where were we while the Pyramid was Collapsing? At a Yoga Class
}

\section{Society and Politics}

\author{
Ruth Whippman ${ }^{1}$
}

Published online: 27 October 2017

(C) Springer Science+Business Media, LLC 2017

The last couple of decades in the US have been the age of selfactualization. The systematic packaging and selling of happiness is an industry estimated to be worth around $\$ 11$ billion (about the same size as Hollywood, the other great purveyors of the happy-ever-after) and in recent years, this industry has found a new respectability. While the words "self-help guru" might once have conjured some kind of sweaty, fist-pumping huckster roaring out platitudes to a desperate crowd, it's now more likely to be an Ivy League 'positive psychology' professor with a string of TED talks and a government contract.

A decade ago, meditation practiced anywhere outside of Tibet or adolescence had the vague whiff of patchouli and dysfunction about it. Now investment bankers do it at their desks and the US military teaches it to the marines. Ancient Eastern wisdom has been repackaged into a multi-billion dollar spiritual-industrial complex, sold to everyone from Silicon Valley billionaires to low-income inner city school children. In a culture that loves consumerism, happiness has become the ultimate consumer product. Even governments are in on the act, with a growing movement underway to push "gross national happiness" as an alternative measure of national prosperity to GDP.

It is tempting to believe that this fascination with selfactualization has sprung up as the result of prosperity. In a society whose basic needs (the base of Maslow's pyramid) are amply satisfied, we now have the time and resources at our disposal to tweak and obsess over the architectural flourishes at the pyramid's tip.

Ruth Whippman

ruthwhippman@gmail.com

1 Abrams Artists Agency, 275 Seventh Avenue, 26th floor, New York, NY 10001, USA
But the reality is more complex, and in many ways more insidious. Although as a whole, Western societies now enjoy unprecedented prosperity, this is a deeply misleading picture of the lived realities of the vast majority of the population.

Despite stratospheric growth in the incomes of the top $1 \%$ in the last few decades, the wages of the other $99 \%$ have stagnated or even, for several demographics, fallen. Meanwhile the costs of the absolute fundamentals that form the base of Maslow's pyramid- in particular housing and healthcare- have skyrocketed.

The economics of this add up to a grim picture. Around 10 million people in America work full time but still live below the official poverty line. Even many professionals are now failing to make a living wage. Over half of Americans do not have $\$ 400$ on hand to tackle an emergency. Housing is in crisis- on the wealthy coasts, even the bulk of the middle classes are now unable to afford to live in the boom cities in which they work. In middle America, housing is cheaper but jobs are hard to come by, leading to mass disaffection in rust belt communities. There is not a single congressional district in America in which a full-time minimum wage worker can afford fair market rent for a two-bedroom apartment. Over 33 million people do not have health insurance, and many more have insurance that is so bad that it is essentially worthless.

It would be easy to argue that the people who are frantically pursuing self-actualization are different people from those who are struggling. That the yoga classes and self-help books are the preserve of the privileged, who already have the fundamentals in place. But increasingly this is not so.

We have developed a new and pervasive cultural narrative around human wellbeing that has seeped through virtually sections of society. This narrative inverts Maslow's pyramid, positing self-realization not just as something to pursue when the basic fundamentals are in place, but as a viable alternative to those fundamentals. 
We have collectively adopted a kind of neoliberalism of the emotions. Rather than seeing psychological health and flourishing as the result of a basic social contract that aims to provide for all, we are increasingly seeing it as the result of individual effort, divorced from our circumstances or the societies in which we live.

The positive psychology movement, which is now highly influential with government policy makers and business leaders, has heavily pushed the idea that circumstances are of minimal importance to wellbeing. In her book, The How of Happiness, a set text on many of the academic positive psychology courses in the country, Professor Sonja Lyubomirsky of UC Riverside, provides a pie chart that estimates the portion of our happiness determined by our material circumstances at just $10 \%$, while the amount under our own control, to be manipulated by our own effort at around $40 \%$ (in reality these figures are highly disputable, and based on both flawed logic and flawed data.) As Professor Martin Seligman of the University of Pennsylvania, the founding father of the positive psychology movement put it in an interview "your troubles are brought on by you. You are responsible for them." In memespeak, we now insist that "happiness is a choice."

This emphasis on individual control has led to an almost belligerent denial in recent years of the impact of social and political context on wellbeing. We are encouraged to turn to self-help books rather than social safety nets, and blame the individual for his or her own unhappiness rather than attempting to tackle the thorny causes behind it.

Oprah Winfrey, widely acknowledged to be one of the most influential people in American culture over the last 25 years or so has played a key role in this. Resolutely a-political, her signature brand of self-improvement and 'living your best life' defiantly ignores any structural obstacles that might stand in the way of this lofty aim, while refusing to acknowledge that the deck might be stacked.

For example, on one episode of her eponymous show, devoted to the promotion of the wildly popular self-help book, The Secret, she focuses on the topic of gratitude, a key technique in the wider positive psychology and self-help literature. Clarissa, a single mother in the studio audience tells Oprah that she has been fired from her job without cause or due process. She is sliding into poverty and is scared for her own future and that of her young toddler. But rather than engaging with the facts of the case, or acknowledging the astonishing lack of legal protection for American employees compared with virtually any other developed country, Oprah tells her: "any time you get fired, you should say 'thank you' because it obviously means you weren't supposed to be there." She goes on to urge Clarissa to accept that the problem "wasn't him, it was me....I was negative" and even to write the former boss a letter of thanks for his decision which was read out on a later episode of the show to rousing applause. As Clarissa's abstract journey of personal growth trumped the possibility of a living wage, Maslow's pyramid was turned on its head.
Increasingly companies in the low wage economy are using the rhetoric and promise of self-actualization as a handy cover for exploitation.

Companies offering low wage, zero security jobs without benefits or healthcare advertise these conditions not as a regrettable necessity, but as a route to self fulfillment. Uber entices new drivers with the promise that they can "be their own boss" and "live their dreams." Lyft's social media team proudly shared a story of a heavily pregnant woman who went into labor while driving and stopped to pick up a customer en route to the hospital, as an exciting example of the "entrepreneurial spirit" of the "Lyft community." Young college graduates are encouraged to 'follow their passions,' which tends to involve lengthy stints of unpaid labor to get a foothold in badly paid but prestigious careers. As a journalist, I am ever familiar with offers of payment for articles in 'exposure' and 'prestige' rather than actual cash.

Across corporate America similar trends are in evidence. Employers are offering a shot at self-actualization as a substitute for adequate pay and benefits. Exhausted office workers are now offered mindfulness classes rather than vacation benefits and healthcare. Walmart, America's largest employer, has rolled out a $\$ 30$ million 'personal development' program for its blue collar workforce, the same employees that are often without health insurance and are largely dependent on food stamps to supplement poverty level wages.

And the more companies use the language and promise of self-actualization in the workplace, the more they tend to strip back the actual fundamentals of decent employment- job security, healthcare, vacation and maternity benefits and pension contributions. The happiness at work movement is often explicitly or implicitly anti-union, the one surefire way that workers gain any meaningful bargaining power.

We are focusing on the tip of Maslow's pyramid at the clear expense of its base. The examples are multiple. Coffee behemoth Starbucks, whose CEO gave a talk at corporate mindfulness conference Wisdom 2.0 entitled "Activating Starbucks Values-Being Present to Inspire and Nurture the Human Spirit," was found by the National Labor Relations Board to have "mounted an antiunion campaign aimed at tracking and restricting the growth of union activities, during which it employed a number of restrictive and illegal policies."1

Bank of America, who stuck high-tech happiness monitors on their call center staff and sent their managers on 'happiness

\footnotetext{
${ }^{1}$ National Labor Relations Board, case number 02-CA-037548. Starbucks lost the case on a number of counts. National Labor Relations Board v. Starbucks Corporation, decided, May 10, 2012. "Starbucks mounted an anti-union campaign aimed at tracking and restricting the growth of pro-union sentiment. In the course of this campaign, Starbucks employed a number of restrictive and illegal policies. These included prohibiting employees from discussing the union or the terms and conditions of their employment; prohibiting the posting of union material on bulletin boards in employee areas; preventing off-duty employees from entering the back area of one of the stores; and discriminating against pro-union employees regarding work opportunities."
} 
training courses' recently settled a huge-scale class action lawsuit brought by employees across the country alleging multiple wage and hours violations including failure to pay overtime and provide adequate rest breaks. The bank settled for seventy-three million dollars. ${ }^{2}$

As one former employee of another major corporation summed it up, "At my company, positive psychology is a euphemism for spin. They try to spin their employees so much that they forget they do the work of three people, have no health insurance, and three quarters of their paycheck goes on rent."

Maslow's model may not be perfect, but in the modern economy, policy makers, and those looking to explain the recent political shocks and voter disaffection would do well to revisit it. Because although self-actualization is important to human flourishing, without the fundamentals of affordable shelter, healthcare and a living wage, it means little.

Ruth Whippman is an author, journalist and documentary film-maker from London, living in the USA. Ruth's humorous essays and comment pieces have appeared in The New York Times, Time Magazine, The Guardian, The Independent, The Huffington Post, Glamour Magazineand The Pool among other places. She is a regular contributor to Time.com and a blogger for the Huffington Post. She is the author of America the Anxious, How Our Pursuit of Happiness is Creating a Nation of Nervous Wrecks (St Martin's/ Macmillan, 2016).

${ }^{2}$ Bank of America Wage and Hour Employment Practice Litigation, United States District Court of Kansas, Case 10-MD-2138-JWL-KGS, document 653-1, Dec. 18, 2013, http://www.ksd.uscourts.gov/settlement-agreementwith-attachments-doc-653-2/. 